\title{
Epidemiologic aspects of Crohn's disease: a population based study in Olmsted County, Minnesota, 1943-1982
}

\author{
J H GOLlOP, S F PHILlipS, L J MELTON III, AND A R ZINSMEISTER \\ From the Mayo Medical School, Gastroenterology Unit and Department of Health Sciences Research, \\ Mayo Clinic and Mayo Foundation, Rochester, Minnesota, USA
}

SUMmaRY The overall age and sex adjusted incidence of Crohn's disease among Olmsted County, Minnesota, residents was $4 \cdot 0$ per 100000 person-years in the period 1943-1982. Ileitis, ileocolitis, and colitis each accounted for about one third of the 103 incidence cases. Incidence rates were greater in woman than men, were higher in the urban portions of the county, and rose over time. Overall, the natural history of Crohn's disease in the community may be milder than that reported for patients at referral centres, as over half of all patients had no complications and only a third required surgery for Crohn's disease. Only one developed adenocarcinoma of the colon (relative risk $=2 \cdot 0, \mathrm{NS}$ ). Survival was relatively unimpaired for the cohort, but Crohn's disease may have played a role in half of the deaths. The prevalence of Crohn's disease was 90.5/100000 population on 1 January 1980.

Chronic granulomatous transmural inflammatory disease of the bowel (Crohn's disease) was recognised as a distinct entity only in this century. More than 50 years after identification and characterisation of Crohn's disease, its cause remains unknown, although incidence and prevalence rates are reported to be increasing. ${ }^{1-3}$ The natural history of the disease appears to vary between centres, and appropriate treatment remain unsettled. ${ }^{4}$

The aim of this investigation was to determine the epidemiologic characteristics of Crohn's disease in the geographically defined population of Olmsted County, Minnesota. In addition to describing the clinical spectrum at diagnosis and subsequent natural history in community residents, we examined secular trends in the incidence of Crohn's disease over a 40 year period and determined prevalence as of 1 January 1980.

Address for correspondence: Dr Sidney F Phillips, Gastroenterology Unit, Mayo Clinic, Rochester, Minnesota 55905, USA.

Received for publication 2 July 1987.

\section{Methods}

SUBJECTS

Population based epidemiologic research is possible in Olmsted County, Minnesota, because medical care is virtually selfcontained within the community and is delivered by a handful of providers. Most care is provided by the Mayo Clinic, which has maintained a common medical record system with its two large affiliated hospitals over the past 70 years. This dossier type medical record contains both inpatient and outpatient data and is easily retrievable for review. The diagnoses and surgical procedures entered into these records are indexed. The index includes the diagnoses made for outpatient office or clinic consultations, emergency room visits, nursing home care, hospitalisations, autopsy examination, and death certification. The medical records of the other medical care providers in the area who have served the local population are also indexed and retrievable. Thus, all details of the medical care provided to the residents of Olmsted County are available for study.

Using this unique data base, we identified 103 individuals who were residents of Olmsted County 
when first diagnosed as having Crohn's disease in the 40 year period, 1943-1982. To assure complete case ascertainment, records were screened, beginning in 1935 , of all cases designated by any of the following diagnoses: Crohn's disease, regional enteritis, regional ileitis, terminal ileitis, granulomatous colitis, hyperplastic ileocolitis, cicatrising ileitis, segmental colitis, regional (ulcerative) colitis, and unspecified or non-specific inflammatory bowel disease. Records of patients with chronic ulcerative colitis (CUC) and related diagnoses were also screened for Crohn's disease in a concurrent study. ${ }^{6}$ The histories of patients who had inflammatory bowel disease, but in whom a clear distinction between CUC and Crohn's colitis was lacking, were reevaluated and their tissue specimens reassessed by one of our pathologists. We were thus able to assign each of these mixed cases to one study or the other. Between the two studies, there was no overlap or exclusion of inflammatory bowel disease cases.

A diagnosis of Crohn's disease for purposes of this study required at least two of the following: (1) History of abdominal pain, weight loss, malaise, rectal bleeding and/or diarrhoea. (2) Characteristic findings at endoscopy of discontinuous ulceration, cobblestoning, fistula, and/or severe perianal disease. (3) Radiologic features of stricture, fistula, and/or evidence of cobblestoning or ulceration of the mucosa. (4) Macroscopic appearance at laparotomy of typical bowel wall induration, mesenteric lymphadenopathy, and serosal involvement showing creeping fat or other inflammatory changes. (5) Histopathology showing transmural inflammatory cell infiltrate, and/or epithelioid granulomas, and absence of identifiable infectious agents.

Findings must have been of at least six months' duration, thus excluding cases of acute enteritis. Cases of infectious enteritides and colitides, as well as ischaemic bowel disease, were excluded after careful

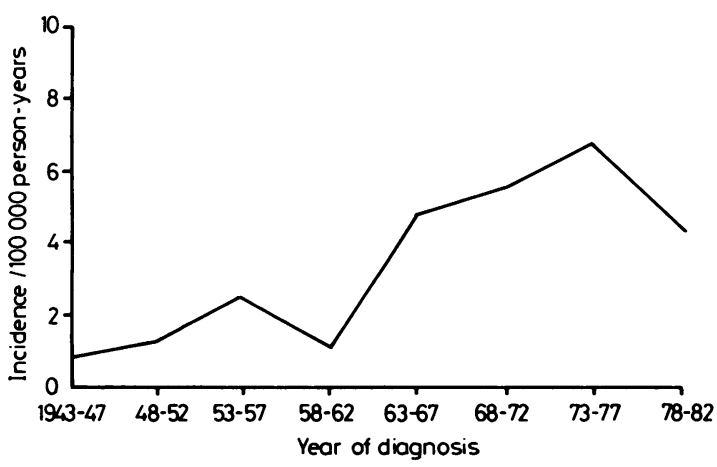

Fig. 1 Secular trends in the age and sex adjusted incidence of Crohn's disease among residents of Olmsted County, Minnesota, 1943-1982.
Table 1 Incidence of Crohn's disease among residents of Olmsted County, Minnesota, 1943-1982, by sex and time period

\begin{tabular}{|c|c|c|c|c|c|c|}
\hline \multirow{3}{*}{$\begin{array}{l}\text { Age-group } \\
\text { (years) }\end{array}$} & \multicolumn{6}{|c|}{ Women } \\
\hline & \multicolumn{2}{|c|}{$1943-1962$} & \multicolumn{2}{|c|}{$1963-1982$} & \multicolumn{2}{|c|}{ All years } \\
\hline & $n$ & Rate $^{*}$ & $n$ & Rate* $^{*}$ & $n^{*}$ & Rate $^{*}$ \\
\hline$<15$ & 0 & - & 2 & $0 \cdot 8$ & 2 & $0 \cdot 5$ \\
\hline $15-24$ & 3 & $3 \cdot 1$ & 22 & 13.4 & 25 & $9 \cdot 6$ \\
\hline $25-34$ & 1 & 1.2 & 14 & $9 \cdot 8$ & 15 & $6 \cdot 7$ \\
\hline $35-44$ & 3 & $4 \cdot 4$ & 10 & $10 \cdot 4$ & 13 & 7.9 \\
\hline $45-54$ & 1 & 1.7 & 3 & $3 \cdot 8$ & 4 & $2 \cdot 9$ \\
\hline $55-64$ & 0 & - & 4 & $6 \cdot 1$ & 4 & $3 \cdot 6$ \\
\hline$\geq 65$ & 1 & $2 \cdot 1$ & 2 & $2 \cdot 2$ & 3 & $2 \cdot 1$ \\
\hline \multirow[t]{4}{*}{ Subtotal } & 9 & $1 \cdot 6$ & 57 & $6 \cdot 4$ & 66 & $4 \cdot 6$ \\
\hline & \multicolumn{6}{|c|}{ Men } \\
\hline & \multicolumn{2}{|c|}{$1943-1962$} & \multicolumn{2}{|c|}{$1963-1982$} & \multicolumn{2}{|c|}{ Allyears } \\
\hline & $n$ & Rate* & $n$ & Rate $^{*}$ & $n$ & Rate* \\
\hline$<15$ & 1 & $0 \cdot 6$ & 3 & $1 \cdot 2$ & 4 & $1 \cdot 0$ \\
\hline $15-24$ & 0 & - & 11 & 9.0 & 11 & 5.9 \\
\hline $25-34$ & 2 & $2 \cdot 6$ & 9 & $6 \cdot 8$ & 11 & $5 \cdot 3$ \\
\hline $35-44$ & 0 & - & 4 & $4 \cdot 2$ & 4 & $2 \cdot 5$ \\
\hline $45-54$ & 1 & 1.9 & 2 & $2 \cdot 7$ & 3 & $2 \cdot 4$ \\
\hline $55-64$ & 1 & $2 \cdot 5$ & 1 & $1 \cdot 8$ & 2 & $2 \cdot 1$ \\
\hline$\geq 65$ & 1 & $2 \cdot 6$ & 1 & $1 \cdot 8$ & 2 & $2 \cdot 1$ \\
\hline Subtotal & 6 & $1 \cdot 2$ & 31 & 3.9 & 37 & $2 \cdot 9$ \\
\hline Total & 15 & $1 \cdot 4$ & 88 & $5 \cdot 2$ & 103 & $3 \cdot 8$ \\
\hline
\end{tabular}

${ }^{*}$ Incidence $/ 100000$ person-years.

review. Only cases we felt confident in categorising as 'definite Crohn's disease' were included in this study. A priori, incidence cases must also have been residents of Olmsted County for one year before diagnosis. This rule was intended to introduce a conservative bias by excluding patients who may have moved into the community for care of the disease before diagnosis; as it happened, however, no patients were excluded on these grounds. Patients who had the disease before moving to the area were not included as incidence cases but were counted as prevalence cases if still alive and residing in Rochester on 1 January 1980 . Of the 82 prevalence cases, 59 were also incidence cases; two were initially diagnosed in Olmsted County before 1943; and the remaining 21 had the diagnosis established elsewhere before moving into the community, mostly from other towns in the region.

For calculating incidence and prevalence rates, the entire population of Olmsted County, Minnesota, was considered to be at risk; the denominator age and sex specific person-years ( $p-y)$ were derived from decennial census figures.' Incidence rates were calculated separately for Rochester, the urban centre of Olmsted County, and for the balance of the county, 
which is largely rural. Where necessary, rates were directly age and/or age and sex adjusted using United States whites in 1980 as the standard population. Ninety five per cent confidence intervals for the rates $(95 \% \mathrm{CI})$ were estimated assuming that the incidence cases follow a Poisson distribution. ${ }^{\times}$The influence of age, sex, urban, or rural residence, and time period, and their possible interactions, were assessed by an analysis of variance, using a rank transformation of the individual age and sex specific incidence rates. Statistical significance indicates $\mathrm{p}<0.05$ unless otherwise noted.

Patients were followed through their records in the community until death or the date of the last medical record entry. Follow up was complete to death or through 1980 in $92 \%$ (median, $9 \cdot 0$ years of follow up per person); the median duration of follow up was $8 \cdot 1$ years in the remainder. The observed incidence of colorectal adenocarcinoma in this group was compared with the expected incidence (relative risk). The expected incidence was calculated using the age and sex specific person-years of follow up in the cohort in conjunction with age and sex specific incidence rates of colorectal adenocarcinoma (sarcoma excluded) previously determined for Rochester residents. ${ }^{9}$ A $95 \%$ confidence interval around the relative risk estimate was calculated assuming that the incidence of colorectal cancer in this cohort follows a Poisson distribution. Life table analysis (product limit method) "10 was used to estimate observed and expected survival, using as a standard the death rates of West North Central United States residents in 1970. The difference between observed and expected survival was assessed with the log-rank test." Life table methods were also used to estimate the cumulative incidence of complications (survival free of complications).

\section{Results}

OVERALL INCIDENCE AND PREVALENCE

During the 40 year period of study, 103 incidence cases were identified in the population for an overall crude incidence rate of 3.8/100000 p-y (sex and age adjusted, 4.0/100000 p-y; 95\% CI 3.2-4.8). The overall age and sex adjusted incidence was $4.6 /$ 100000 p-y in the city of Rochester ( $\approx$ urban) and only $2 \cdot 8 / 100000 \mathrm{p}-\mathrm{y}$ in the balance of Olmsted County $(\approx$ rural $)$. In the County as a whole, adjusted incidence rates rose from $0 \cdot 8 / 100000 \mathrm{p}$-y in 1943 1947 to $6 \cdot 8 / 100000$ p-y in $1973-1977$ and then fell to $4 \cdot 3 / 100000$ p-y for $1978-1982$ (Fig. 1). Roughly the same temporal pattern was seen for the urban residents of Rochester and for those who resided in the rural areas of Olmsted County.

Among incidence cases, women outnumbered men 66 to 37. Incidence rates for women were correspondingly higher, but the sex ratio was reduced to $1 \cdot 5: 1$ by age adjustment of the rates (women, $4 \cdot 8$ per $100000 \mathrm{p}-\mathrm{y}, v$ men, $3 \cdot 1$ per $100000 \mathrm{p}-\mathrm{y})$. Most of the female excess, however, was in the last half of the study (Table 1). In the period 1963-1982, rates were somewhat greater for women in most age groups, while sex specific rates were more comparable in 1943-1962. In general, age specific incidence rates were greatest among young adults of both sexes, although this was most clear in the latter half of the study period. Patterns for urban and rural residents were similar considering the relatively small number of cases.

Prevalence rates were also greater among women than men, but cases were shifted into a somewhat older age distribution compared with incidence cases (Table 2). The prevalence of Crohn's disease on 1 January 1980 was also greater in Rochester than in rural Olmsted County (adjusted 107.0 v 61.8 per 100000 , respectively). The overall age and sex adjusted prevalence of Crohn's disease in Olmsted County was $91 \cdot 0 / 100000$ population on 1 January $1980(95 \%$ CI $71 \cdot 0-110 \cdot 9)$.

All patients were white, except for one woman who identified herself as being of mixed black and white ancestry. Four of the patients identified themselves as Jewish at the time of diagnosis. This may be significant because the Jewish population of Rochester is probably less than 300 people at present. At the time of diagnosis, $38(37 \%)$ of the patients were single (never married) as compared with $27 \%$ of the population over 14 years of age at the 1970 census of Olmsted County residents; $61(59 \%)$ patients were married. One was divorced, and the remaining three patients were widowed. The proportion of patients who were professionals at diagnosis $(18 \%)$ was somewhat less than expected $(26 \%)$, based on the 1970 census for Olmsted County, while unskilled laborers $(14 \%)$ were over-represented compared

Table 2 Prevalence of Crohn's disease among residents of Olmsted County, Minnesota, on 1 January 1980, by sex

\begin{tabular}{|c|c|c|c|c|c|c|}
\hline \multirow{2}{*}{$\begin{array}{l}\text { Age-group } \\
\text { (years) }\end{array}$} & \multicolumn{2}{|c|}{ Men } & \multicolumn{2}{|c|}{ Women } & \multicolumn{2}{|c|}{ Bothsexes } \\
\hline & $n$ & Rate* & $n$ & Rate* & $n$ & Rate* \\
\hline$<15$ & () & 0 & () & 0 & () & () \\
\hline $15-24$ & 8 & $98 \cdot 8$ & 5 & $52 \cdot 7$ & 13 & 73.9 \\
\hline $25-34$ & 8 & $102 \cdot 3$ & 15 & $178 \cdot 5$ & 23 & $141 \cdot 8$ \\
\hline $35-44$ & $6)$ & & 18 & $307 \cdot 1$ & 24 & $206 \cdot 9$ \\
\hline $45-54$ & $1\}$ & $7(0.9$ & 5 & $121 \cdot 5$ & 6 & $72 \cdot 7$ \\
\hline $55-64$ & $4)$ & & 3 & $86 \cdot 1$ & 7 & $105 \cdot 3$ \\
\hline$\geq 65$ & $1\}$ & $8(0) \cdot()$ & 8 & $147 \cdot 2$ & 9 & $105 \cdot 6$ \\
\hline Total & $28^{\prime}$ & $64 \cdot 9$ & 54 & 113.9 & 82 & $90 \cdot 5$ \\
\hline
\end{tabular}

${ }^{*}$ Prevalence/ 100000 population on 1 January 1980. 
with census data $(2 \%)$. Incidence rates could not be calculated for specific religions or occupations.

CIINICAL SPECTRUM AT DIAGNOSIS

The median delay from onset of symptoms to diagnosis was just over four months. One patient was diagnosed with Crohn's disease simultaneously with the onset of symptoms, while five patients had had symptoms for 10 years or more before initial diagnosis. In two patients, the duration of symptoms could not be determined as they were asymptomatic and diagnosed incidentally.

The extent of bowel involvement at the time of initial diagnosis is shown in Figure 2. Overall, $67 \%$ had involvement of the small bowel (all with involvement of the distal or terminal ileum) and $59 \%$ had disease of the colon. Rectal and/or anal disease was seen in $30 \%$. When the patients were divided into mutally exclusive groups, $36(35 \%)$ had ileitis alone; $30(29 \%)$ had ileocolitis; and $37(36 \%)$ had colitis alone. Age and sex specific incidence rates for these three manifestations of Crohn's disease were similar, as were the total incidence rates for each type (Table 3).

\section{CLINICAL COURSE}

Thirteen patients had unremitting disease, while 75 $(73 \%)$ experienced a chronic intermittent course. Ten patients $(10 \%)$ were 'cured' in the sense of going at least 10 years with no evidence of disease after resection, becoming asymptomatic with negative radiographic findings, or having only old scarring which did not progress. The nature of the clinical course could not be adequately characterised in five patients. Unremitting disease seemed to be more frequent among those with colonic involvement (Table 4).

The maximal extent of disease during the period of follow up is also shown in Figure 2. Altogether, $60 \%$ of the patients had progressed to more extensive disease or resection by the period of maximum disease. The proportions of patients with progression were similar for Crohn's patients with ileitis, ileocolitis, or colitis (Table 4). To some degree, progression was a function of duration of follow up which was longer (median $10 \cdot 8$ years) for those with progression as opposed to those without progression (median 6.() years). By the point of maximal disease, a third of all patients had had at least some bowel resected (Fig. 2 and Table 4 ).

Fifty nine per cent of patients had an uncomplicated course, while the remainder developed one or more complications of Crohn's disease (Table 4). There was no clear pattern of complications by site except that patients with Crohn's colitis seemed to have fewer of them. The cumulative incidence of complications reached $19 \%$ by the end of the first year after the diagnosis of Crohn's and doubled again to $38 \%$ by the end of the first decade of follow up. At the 5 year point, $41 \%$ of ileitis patients and $47 \%$ of those with Crohn's ileocolitis had experienced one or more complications, compared with only $12 \%$ of patients with Crohn's colitis.

One man developed a histologically confirmed

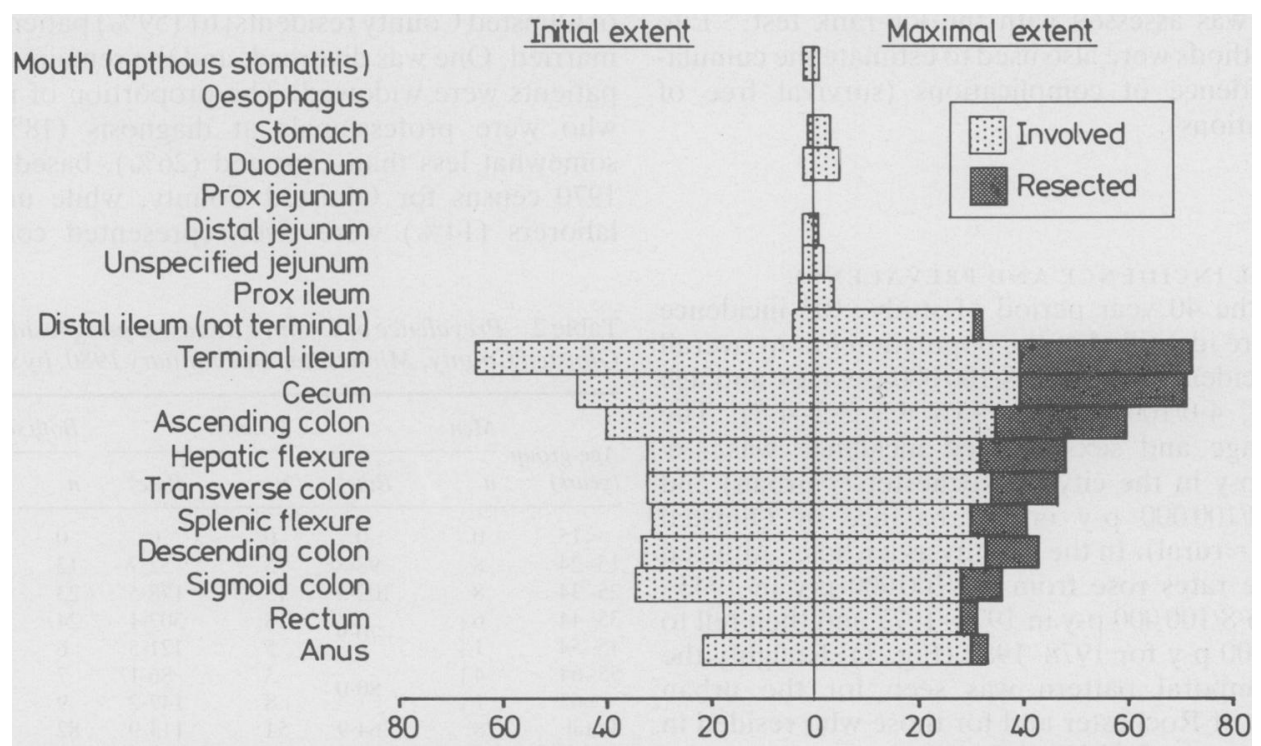

Fig. 2 Distribution (\%) of affected sites initially (left panel) and maximally (right panel) among Olmsted County, Minnesota, residents diagnosed with Crohn's disease, 1943-1982. 
Table 3 Incidence of Crohn's disease among residents of Olmsted County, Minnesota, by extent of bowel involvement at the time of initial diagnosis, 1943-1982

\begin{tabular}{|c|c|c|c|c|c|c|}
\hline \multirow{2}{*}{$\begin{array}{l}\text { Sexand } \\
\text { age-group } \\
\text { (years) }\end{array}$} & \multicolumn{2}{|c|}{ Ileitis } & \multicolumn{2}{|c|}{ Ileocolitis } & \multicolumn{2}{|c|}{ Colitis } \\
\hline & $n$ & Rate* & $n$ & Rate $^{*}$ & $n$ & Rate $^{*}$ \\
\hline \multicolumn{7}{|l|}{ Men } \\
\hline$<15$ & 1 & $0 \cdot 2$ & 1 & $0 \cdot 2$ & 2 & 0.5 \\
\hline $15-24$ & 4 & $2 \cdot 1$ & 5 & $2 \cdot 7$ & 2 & $1 \cdot 1$ \\
\hline $25-34$ & 3 & 1.4 & 4 & 1.9 & 4 & 1.9 \\
\hline $35-44$ & () & 0 & 1 & 0.6 & 3 & 1.9 \\
\hline $45-54$ & 2 & $1 \cdot 6$ & 1 & 0.8 & () & 0 \\
\hline $55-64$ & 1 & $1 \cdot 0$ & 0 & 0 & 1 & $1 \cdot 0$ \\
\hline$\geq 65$ & 1 & $1 \cdot 1$ & 1 & $1 \cdot 1$ & 0 & 0 \\
\hline Subtotal & 12 & 0.9 & 13 & $1 \cdot 0$ & 12 & 0.9 \\
\hline \multicolumn{7}{|l|}{ Women } \\
\hline$<15$ & 1 & $0 \cdot 3$ & 1 & $0 \cdot 3$ & () & 0 \\
\hline $15-24$ & 9 & $3 \cdot 5$ & 8 & $3 \cdot 1$ & 8 & $3 \cdot 1$ \\
\hline $25-34$ & 4 & $1 \cdot 8$ & 3 & $1 \cdot 3$ & 8 & $3 \cdot 6$ \\
\hline $35-44$ & 6 & $3 \cdot 7$ & 2 & $1 \cdot 2$ & 5 & $3 \cdot 1$ \\
\hline $45-54$ & 2 & $1 \cdot 5$ & 1 & 0.7 & 1 & 0.7 \\
\hline $55-64$ & 1 & 0.9 & 2 & $1 \cdot 8$ & 1 & 0.9 \\
\hline$\geq 65$ & 1 & 0.7 & () & 0 & 2 & $1 \cdot 4$ \\
\hline Subtotal & 24 & $1 \cdot 7$ & 17 & $1 \cdot 2$ & 25 & $1 \cdot 7$ \\
\hline Total & 36 & $1 \cdot 3$ & 30 & $1 \cdot 1$ & 37 & $1 \cdot 4$ \\
\hline
\end{tabular}

${ }^{*}$ Incidence 100000 person-years. Age and sex specific rates are shown despite the small number of cases in some cells.

adenocarcinoma of the rectum in an area involved with Crohn's and died of this at age 30,17 years after diagnosis of Crohn's disease. The expected number of cases in a group of like age and sex distribution and comparable follow up is $0.5(\mathrm{RR}=2 \cdot 0 ; 95 \% \mathrm{CI} 0.1$ to $11 \cdot 1)$. Another woman developed a histologically confirmed leiomyosarcoma of the ileum in an involved area and died at age 63, 31 years after the initial diagnosis of Crohn's. She had received radiation treatment for her Crohn's disease, as was popular during the 1940's and 50's, which may have been a contributing factor. The expected number of such cases was not calculated because of the absence of suitable incidence rates for the general population of Olmsted County.

SURVIVAL

Up to the time of last follow up, 93 of the incidence patients were alive, while 10 had died. Of the 10 Crohn's disease was the primary cause of death in three (secondary to inanition at age 17, peritonitis at age 62 , and bowel obstruction and perforation at age 67 , respectively). As already mentioned, two patients died from GI malignancy in areas involved with Crohn's, so their deaths may also have been disease related. The other five deaths in this cohort seemed unrelated to Crohn's disease. Despite the deaths related to Crohn's disease, the overall survival experience of the cohort was only modestly less than

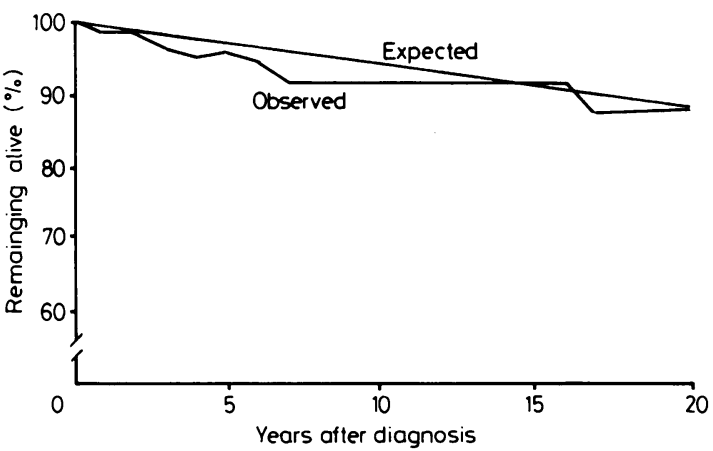

Fig. 3 Observed and expected survival after the initial diagnosis of Crohn's disease among residents of Olmsted County, Minnesota, 1943-1982.

that expected for members of the general population of like age and sex (Fig. 3). Survival, relative to that expected, was equally good for those with Crohn's ileitis, ileocolitis, and colitis. Over $90 \%$ of patients in each group were still alive 10 years after the initial diagnosis of Crohn's disease.

\section{Discussion}

Incidence rates for Crohn's disease in Olmsted County, Minnesota, resemble figures from similar studies in British communities. Overall rates from England and Wales ${ }^{11-14}$ are quite close to the Olmsted County rate of $5 \cdot 6 / 100000$ p-y for a comparable time period, as are figures from Sweden. ${ }^{15-17}$ Other studies from northern Europe report lower rates, ${ }^{18-24}$ but the discrepancies between these figures and the Southeastern Minnesota rates are not as great as seen for chronic ulcerative colitis. ${ }^{6}$ Differences may be the result of variations in study timing, definitions, and completeness of case ascertainment. For example, the secular increase in Crohn's disease incidence that has been observed in the majority of epidemiologic studies worldwide since the 1930 's ${ }^{25}$ suggests that lower rates should apply to studies conducted in earlier years. The much lower rates in the Oxford study, ${ }^{18}$ on the other hand, seem to be due to the exclusion of Crohn's colitis. Colitis patients comprised over a third of the present cohort, and the proportions of patients with ileitis, ileocolitis, and colitis were about equal to those seen during comparable periods in other areas. ${ }^{11219202126}$ Studies based solely on hospitalised cases generally produce low incidence rates. ${ }^{26-34}$ Rates most similar to those in Olmsted County were obtained from comparable studies based on all diagnosed cases (outpatient as well as inpatient). Because of access to a comprehensive medical record linkage and indexing system, we believe our data include all cases of Crohn's disease 
Table 4 Clinical course and complications observed among Olmsted County, Minnesota, residents diagnosed with Crohn's disease, 1943-1982, by site of involvement

\begin{tabular}{|c|c|c|c|c|c|c|c|c|}
\hline \multirow[b]{2}{*}{ Course } & \multicolumn{2}{|c|}{ Ileitis } & \multicolumn{2}{|c|}{ Ileocolitis } & \multicolumn{2}{|c|}{ Colitis } & \multicolumn{2}{|c|}{ Total } \\
\hline & $n$ & $\%$ & $n$ & $\%$ & $n$ & $\%$ & $n$ & $\%$ \\
\hline Unremitting & 1 & $2 \cdot 8$ & 5 & $16 \cdot 7$ & 7 & $18 \cdot 9$ & 13 & $12 \cdot 6$ \\
\hline Chronic intermittent & 30 & $83 \cdot 3$ & 19 & $63 \cdot 3$ & 26 & $70 \cdot 3$ & 75 & $72 \cdot 8$ \\
\hline 'Cured' & 3 & $8 \cdot 3$ & 5 & $16 \cdot 7$ & 2 & $5 \cdot 4$ & 10 & $9 \cdot 7$ \\
\hline Undetermined & 2 & $5 \cdot 6$ & 1 & $3 \cdot 3$ & 2 & $5 \cdot 4$ & 5 & 4.9 \\
\hline \multicolumn{9}{|l|}{ Progression } \\
\hline Yes & 20 & $55 \cdot 6$ & 18 & $6(0) \cdot 0$ & 24 & $64 \cdot 9$ & 62 & $60 \cdot 2$ \\
\hline \multicolumn{9}{|l|}{ Bowel resection } \\
\hline Yes & 19 & $52 \cdot 8$ & 13 & $43 \cdot 3$ & 4 & $10 \cdot 8$ & 36 & $35 \cdot()$ \\
\hline \multicolumn{9}{|l|}{ Complications* } \\
\hline $\begin{array}{l}\text { Small bowel obstruction due to Crohn's disease } \\
\text { and necessitating surgery }\end{array}$ & 13 & $36 \cdot 1$ & 4 & $13 \cdot 3$ & 0 & 0 & 17 & $16 \cdot 5$ \\
\hline Enteroenteric or enterocolonic fistula & 4 & $11 \cdot 1$ & 4 & $13 \cdot 3$ & 1 & $2 \cdot 7$ & 9 & $8 \cdot 7$ \\
\hline Fistula to abdominal abscess & 1 & $2 \cdot 8$ & 5 & $16 \cdot 7$ & 2 & $5 \cdot 4$ & 8 & $7 \cdot 8$ \\
\hline Serious haemorrhage & 1 & $2 \cdot 8$ & 3 & $10 \cdot()$ & 2 & $5 \cdot 4$ & 6 & $5 \cdot 8$ \\
\hline Enterovaginal fistula & () & 0 & 3 & $10 \cdot 0$ & 2 & $5 \cdot 4$ & 5 & 4.9 \\
\hline Enterocutaneous fistula & 1 & $2 \cdot 8$ & 1 & $3 \cdot 3$ & 1 & $2 \cdot 7$ & 3 & $2 \cdot 9$ \\
\hline Free perforation of the bowel & 1 & $2 \cdot 8$ & 1 & $3 \cdot 3$ & 1 & $2 \cdot 7$ & 3 & $2 \cdot 9$ \\
\hline Enterovesical fistula & 1 & $2 \cdot 8$ & 1 & $3 \cdot 3$ & 0 & 0 & 2 & 1.9 \\
\hline Toxic megacolon & () & 0 & 1 & $3 \cdot 3$ & () & 0 & 1 & $1 \cdot 0$ \\
\hline Any of the above & 19 & $52 \cdot 8$ & 16 & $53 \cdot 3$ & 7 & $18 \cdot 9$ & 42 & $40 \cdot 8$ \\
\hline
\end{tabular}

${ }^{*}$ Patients may be counted more than once.

diagnosed among Olmsted County residents during the time of the study.

Incidence rates also rose in Olmsted County over the course of the study. A true increase in incidence would point to an environmental factor $;^{25}$ and a number have been suggested, including more prevalent cigarette smoking ${ }^{35}{ }^{36}$ increasing usage of birth control pills ${ }^{35}{ }^{37}$ and greater exposure to refined carbohydrates in the diet. ${ }^{38}$ The role of increased urbanisation has not been fully explored, although incidence rates have reportedly increased in both urban and rural areas. ${ }^{22}$ Even so, rates remain higher in urban areas, ${ }^{1922}$ as seen also in the present study. It must be admitted, however, that these exposures are ubiquitous, while Crohn's remains a relatively uncommon condition; thus, other factors must be involved. That this is because of better separation of the disease from colonic ulcerative colitis has been discounted. ${ }^{12161719}$ The rise in rates may be partly caused by more complete case acertainment. ${ }^{111339}$ There is some evidence for this in the shortening interval between onset of symptoms and initial diagnosis 171722 and in recent short term declines in incidence in some communities ${ }^{17} 19^{22}$ that may have resulted from sweeping the population free of previously undiagnosed cases. Nonetheless, better recognition, especially of colonic Crohn's, ${ }^{24}$ does not seem sufficient to explain the large increase in cases, particularly during the last two decades in developed nations. ${ }^{131621}$
The prevalence of Crohn's disease in Rochester is substantially greater than that reported elsewhere." $1215-192122+14-22$ Reasons for the higher prevalence may be the same as for higher incidence, namely differences in definitions and under ascertainment of cases elsewhere. The latter is expecially important for prevalence (strictly, the prevalence of a history of the disease) because patients who have had the disease in the past but are no longer seeking care for it may be missed if the study period is relatively short. Thus, the prevalence of Crohn's was nearly $80 \%$ greater in Copenhagen in 1973 after 18 years of study than it was in 1967 after only 12 years $^{16}$ and three times higher in Malmö, Sweden after an additional eight years of study. ${ }^{17}$ For the purpose of identifying prevalence cases, we could take advantage of a previous study extending back to $1935^{+3}$ so ascertainment of cases should have been largely complete. In addition, some investigators calculated prevalence rates using only the prevalence cases that were also incidence cases, " rather than all prevalence cases in the population regardless of time and place of onset; that approach naturally lowers the prevalence rate. In Olmsted County, for example, only $72 \%$ of the prevalence cases were also incidence cases. Finally, if incidence rates have risen, it should also be expected that prevalence would increase because prevalence is a function of both frequency and duration of disease.

The natural history of Crohn's disease in the Olmsted County incidence cohort seems somewhat 
more benign than that reported for patient series from tertiary treatment centres. The $35 \%$ resection rate, for example, is somewhat less than in other population based studies ${ }^{132021}$ and is considerably less than reported in some referral series. ${ }^{44-47}$ The surgical natural history in a cohort of Olmsted County patients with Crohn's has been reported previously. ${ }^{48}$ In addition, more than half of the Olmsted County residents with Crohn's remain free from complications of the disease, even after 15 years of follow up. The two fold increased risk of colon cancer (based on a single observed case) is compatible with the results of some ${ }^{49}$ but not all clinical ${ }^{501}$ studies. The absolute level of risk, however, seems to be low. ${ }^{46505253}$ The relative risk of adenocarcinoma of the small bowel is also said to be raised, ${ }^{153}$ although the absolute incidence may be even smaller. The only small bowel case observed in the present study was a leiomyosarcoma.

Despite the frequent need for surgery and the various complications, survival was not significantly worse in our patients with Crohn's disease than for Olmsted County residents generally. Minimal ${ }^{53}$ or modest ${ }^{15}$ impairments in survival have been documented in other population based studies, while survival is typically worse in referral series..$^{4464750}$ The overall case fatality rate, which varies widely in the literature depending on patient selection and duration of follow up, ${ }^{54}$ was $5 \%$ counting the five Crohn's related deaths. Even though relatively few patients have died thus far, we found, as have others, ${ }^{11} 1520$ that Crohns' disease was frequently implicated.

The authors wish to thank Mr Jon Kosanke for help with computer programming and Ms Mary Ramaker for assistance in preparing the manuscript. This investigation was supported in part by the Mayo Digestive Disease Center and the Rochester/Olmsted County Epidemiology Project, research grants AM 34988 and AM 30582 from the National Institutes of Health.

\section{References}

1 Langman MJS. Chronic non-specific inflammatory bowel disease. In: The epidemiology of chronic digestive disease. London: Edward Arnold Publishers, 1979: 80-102.

2 Mendeloff AI. The epidemiology of inflammatory bowel disease. Clin Gastroenterol 1980; 9: 259-70.

3 Gilat $T$. Incidence of inflammatory bowel disease: Going up or down? Gastroenterology 1983; 85: 196-7.

4 Sachar DB. Crohn's disease in Cleveland: a matter of life and death. Gastroenterology 1985; 88: 1996-8.

5 Kurland LT, Molgaard CA. The patient record in epidemiology. Sci Am 1981; 245: 54-63.
6 Stonnington CM, Phillips SF, Melton LJ, Zinsmeister AR. Chronic ulcerative colitis: Incidence and prevalence in a community. Gut. (In press).

7 Schroeder DJ, Offord KP. A SAS Macro which utilizes local and reference population counts appropriate for incidence, prevalence, and mortality rate calculations in Rochester and Olmsted County, Minnesota. Technical Report Series, no. 20, Section of Medical Research Statistics, Mayo Clinic, Rochester, MN, August, 1982.

8 Beyer WH, ed. CRC handbook of tables for probability and statistics. Cleveland: Chemical Rubber Company, 1966: 58-64 (Table 111.4).

9 Beart RW, Melton LJ, Maruta M, Dockerty MB, Frydenberg HB, O'Fallon WM. Trends in right and leftsided colon cancer. Dis Colon Rectum 1983; 26: 393-8.

10 Kalbfleisch JD, Prentice RL. The statistical analysis of failure time data. New York: J Wiley and Sons, 1980.

11 Devlin HB, Datta D, Dellipiani AW. The incidence and prevalence of inflammatory bowel disease in North Tees Health District. World J Surg 1980; 4: 183-93.

12 Lee FI, Costello FT. Crohn's disease in Blackpool incidence and prevalence $1968-80$. Gut 1985; 26: 274-8.

13 Mayberry J, Rhodes J, Hughes LE. Incidence of Crohn's disease in Cardiff between 1934 and 1977. Gut 1979; 20: 602-60.

14 Mayberry JF, Dew MJ, Morris JS, Powell DB. An audit of Crohn's disease in a defined population. J R Coll Phys Lond 1983; 17: 196-8.

15 Hellers G. Crohns' disease in Stockholm County 19551974: A study of epidemiology, results of surgical treatment and long-term prognosis. Acta Chir Scand 1979; suppl: 490: $1-84$.

16 Bergman L, Krause U. The incidence of Crohn's disease in central Sweden. Scand J Gastroenterol 1975; 10: 725-9.

17 Brahme F, Lindström C, Wenckert A. Crohn's disease in a defined population. Gastroenterology 1975; 69: $342-51$.

18 Evans JG, Acheson ED. An epidemiological study of ulcerative colitis and regional enteritis in the Oxford area. Gut 1965; 6: 311-24.

19 Kyle J, Stark G. Fall in the incidence of Crohn's disease. Gut 1980; 21: 340-3.

20 Fahrländer $\mathrm{H}$, Baerlocher Ch. Clinical features and epidemiological data on Crohn's disease in the Basle area. Scand J Gastroenterol 1971; 6: 657-62.

21 Binder V, Both $\mathrm{H}$, Hansen PK, Hendriksen $\mathrm{C}$, Kreiner S, Torp-Pedersen K. Incidence and prevalence of ulcerative colitis and Crohn's disease in the county of Copenhagen, 1962 to 1978. Gastroenterology 1982; 83: 563-8.

22 Von Brandes J-W, Lorenz-Meyer H. Epidemiologische aspekte zur enterocolitis regionalis Crohn und colitis ulcerosa in Marburg/Lahn (FRG) zwischen 1962 and 1975. Z Gastroenterol 1983; 21: 69-78.

23 Skarstein A, Anesjö B, Burhol P, et al. The incidence of ulcerative colitis and Crohn's disease in an urban population. [Abstract 1389]. Scand J Gastroenterol 1982; 17: suppl 78: 349.

24 Miller DS, Keighley AC, Langman MJS. Changing patterns in epidemiology of Crohn's disease. Lancet 1974; ii: 691-3. 
25 Calkins BM, Mendeloff AI. Epidemiology of inflammatory bowel disease. Epidemiol Rev 1986; 8: 60-91.

26 Humphreys WG. An epidemiological survey of Crohn's disease in northern Ireland. Proc $R$ Soc Med 1975; 68: $572-4$.

27 Smith IS, Young S, Gillespie G, O’Connor J, Bell JR. Epidemiological aspects of Crohn's disease in Clydesdale 1961-1970. Gut 1975; 16: 62-7.

28 Tasman-Jones C, Easen R, Lee SP. Inflammatory bowel disease - ethnic variations in Auckland, New Zealand. [Abstract 1390]. Scand J Gastroenterol 1982; Suppl: 78: 350.

29 Lanfranchi GA, Michelini M, Brignola C, Campieri M, Cortini C, Marzio L. Uno studio epidemiologico sulle malattie inflammatorie intestinali nella provincia di Bologna. G Clin Med 1976; 57: 235-45.

30 Calkins BM, Lilienfeld AM, Garland CF, Mendeloff AI. Trends in incidence rates of ulcerative colitis and Crohn's disease. Dig Dis Sci 1984; 29: 913-20.

31 Garland CF, Lilienfeld AM, Mendeloff AI, Markowitz JA, Terrel KB, Garland FC. Incidence rates of ulcerative colitis and Crohn's disease in fifteen areas of the United States. Gastroenterology 1981; 81: 1115-24.

32 Nunes GC, Ahlquist RE Jr. Increasing incidence of Crohn's disease. Am J Surg 1983; 145: 578-81.

33 Myren J, Gjone E, Hertzberg JN, Rygvold O, Semb LS, Fretheim B. Epidemiology of ulcerative colitis and regional enterocolitis (Crohn's disease) in Norway. Scand J Gastroenterol 1971; 6: 511-4.

34 Tresadern JC, Gear MWL, Nicol A. An epidemiological study of regional enteritis in the Gloucester area. BrJ Surg 1973; 60: 366-8.

35 Vessey M, Jewell D, Smith A, Yeates D, McPherson K. Chronic inflammatory bowel disease, cigarette smoking, and use of oral contraceptives: Findings in a large cohort study of women of childbearing age. Br Med J 1986; 292: 1101-3.

36 Somerville KW, Logan RFA, Edmond M, Langman MJS. Smoking and Crohn's disease. Br Med J 1984; 289: 954-6.

37 Rhodes JM, Cockel R, Allan RN, Hawker PC, Dawson J, Elias E. Colonic Crohn's disease and use of oral contraception. Br Med J 1984; 288: 595-6.

38 Mayberry JF, Rhodes J, Newcombe RG. Increased sugar consumption in Crohn's disease. Digestion 1980; 20: $323-6$.

39 Höj L, Jensen PB, Bonnevie O, Riis P. An epidemiological study of regional enteritis and acute ileitis in Copenhagen County. Scand J Gastroenterol 1973; 8: 381-4.

40 Rozen P, Zonis J, Yekutiel P, Gilat T. Crohn's disease in the Jewish population of Tel-Aviv-Yafo. Gastroenterology 1979; 76: 25-30.

41 Mayberry JF, Rhodes J, Newcombe RG. Crohn's disease in Wales, 1967-1976; An epidemiological survey based on hospital admissions. Postgrad Med J 1980; 56: $336-41$

42 Monk M, Mendeloff AI, Siegel CI, Lilienfeld A. An epidemiological study of ulcerative colitis and regional enteritis among adults in Baltimore. I. Hospital incidence and prevalence. Gastroenterology 1967; 53: 198-210.

43 Sedlack RE, Whisnant J, Elveback LR, Kurland LT. Incidence of Crohn's disease in Olmsted County Minnesota, 1935-1975. Am J Epidemiol 1980; 112: 759-63.

44 DeDombal FT, Burton I, Goligher JC. The early and late results of surgical treatment for Crohn's disease. $\mathrm{Br}$ J Surg 1971; 58: 805-16.

45 Rosenberg IH. 85.3 Crohn's disease. In: Wyngaarden $\mathrm{JB}$, Smith LH Jr, eds. Cecil textbook of medicine. Philadelphia: WB Saunders, 1982: 719.

46 Storgaard L, Bischoff N, Henriksen FW, Fischerman K, Jarnum S. Survival rate in Crohn's disease and ulcerative colitis. Scand J Gastroenterol 1979; 14: 225-30.

47 Farmer RG, Whelan G, Fazio VW. Long-term followup of patients with Crohn's disease: relationship between the clinical pattern and prognosis. Gastroenterology 1985; 88: 1818-25.

48 Agrez MV, Valente RM, Pierce W, Melton LJ III, van Heerden JA, Beart RW Jr. Surgical history of Crohn's disease in a well-defined population. Mayo Clin Proc 1982; 57: 747-52.

49 Gyde SN, Prior P, Macartney JC, Thompson H, Waterhouse JAH, Allan RN. Malignancy in Crohn's disease. Gut 1980; 21: 1024-9.

50 Weedon DD, Shorter RG, Ilstrup DM, Huizenga KA, Taylor WF. Crohn's disease and cancer. $N$ Engl J Med 1973; 289: 1099-103.

51 Greenstein AJ, Sachar DB, Smith H, Janowitz HD, Aufses AH Jr. A comparison of cancer risk in Crohn's disease and ulcerative colitis. Cancer 1981; 48: 2742-5.

52 Greenstein AJ, Sachar DB, Smith H, Janowitz HD, Aufses AH Jr. Patterns of neoplasia in Crohn's disease and ulcerative colitis. Cancer 1980; 46: 403-7.

53 Binder V, Hendriksen C, Kreiner S. Prognosis in Crohn's disease - based on results from a regional patient group from the county of Copenhagen. Gut 1985; 26: 146-50.

54 Mayberry JF, Newcombe RG, Rhodes J. Mortality in Crohn's disease. $Q J$ Med 1980; 49: 63-8. 